\title{
Intrathoracic splenosis: A case report and an update of invasive and noninvasive diagnostic techniques
}

\author{
Enrico Ruffini, MD, ${ }^{a}$ Sofia Asioli, MD, ${ }^{\mathrm{b}}$ Pier Luigi Filosso, MD, ${ }^{a}$ Rebecca Senetta, ${ }^{\mathrm{b}}$ Luigia Macrì,, Antonio Cavallo, MD, \\ and Alberto Oliaro, MD, ${ }^{a}$ Torino, Italy
}

I ntrathoracic splenosis is a rare condition resulting from autotransplantation of splenic tissue into the left side of the chest, usually after diaphragmatic and splenic rupture after blunt or penetrating abdominal trauma. Patients are often free of symptoms, and nodules are usually discovered at computed tomographic scan. Owing to the rarity of the condition (30 cases in the literature so far), most patients undergo thoracotomy before final diagnosis. We present a case of thoracic splenosis that recently came to our attention.

\section{Clinical Summary}

A 67-year-old man had a left upper lobe mass identified during workup for prostatectomy for benign prostate hypertrophy. Medical history was unremarkable except for an injury that had occurred 43 years earlier with rib fractures, pneumothorax, and spleen rupture; no diaphragmatic rupture was evidenced. A chest tube was inserted and a splenectomy was undertaken at that time.

Preoperative workup for the lung lesion included a chest and upper abdominal computed tomographic scan (Figure 1) and fineneedle aspiration of the lesion, revealing a mixture of inflammatory cells comprising mostly lymphocytes, plasma cells, and some pigment-laden macrophages in a background of hemorrhage and endothelial cells. The lymphocytes showed mixed immunoreactivity for CD3 and CD20 whereas tests for pankeratin were negative.

With the suspicion of a neoplastic lesion, the patient underwent a left muscle-sparing thoracotomy. The parietal pleura displayed multiple small $(0.5-1 \mathrm{~cm})$ nodules particularly evident on the diaphragmatic surface. An identical nodule $(3 \times 2 \mathrm{~cm})$ was located along the aorta, from which it could be easily dissected and sent for frozen section examination: grossly, the surgical specimen was soft and displayed, at the cut surface, a brown color with diffuse small white dots (Figure 2, g). Microscopically, it was consistent with a benign spleen, with lymphocytic aggregates and other leukocytes distributed in a highly vascular background of sinusoidal structures (Figure 2, i). No further resection was therefore

\footnotetext{
From the Departments of Thoracic Surgery ${ }^{\mathrm{a}}$ and Pathology, ${ }^{\mathrm{a}}$ University of Torino, Torino, Italy.

Received for publication June 9, 2007; revisions received July 26, 2007; accepted for publication Aug 7, 2007.

Address for reprints: Enrico Ruffini, MD, Thoracic Surgery, University of Torino, 3, Via Genova 10126 Torino, Italy (E-mail: enrico.ruffini@ unito.it).

J Thorac Cardiovasc Surg 2007;134:1594-5

$0022-5223 / \$ 32.00$

Copyright @ 2007 by The American Association for Thoracic Surgery doi:10.1016/j.jtcvs.2007.08.004
}

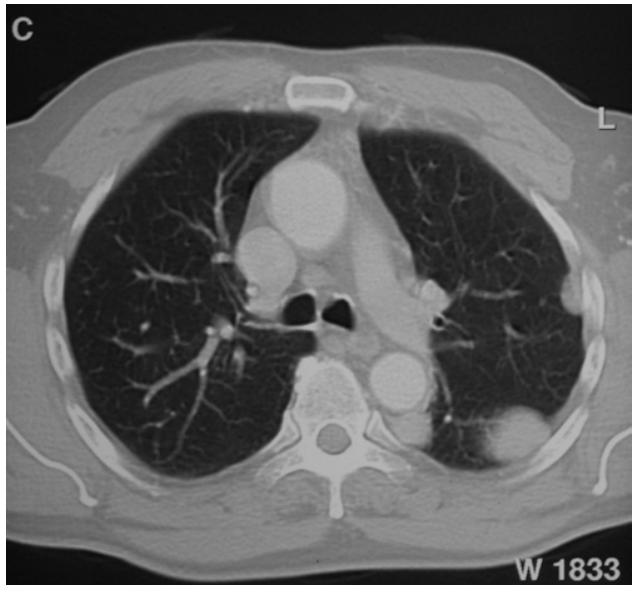

Figure 1. Preoperative computed tomographic scan showing 3 lesions in the left hemithorax.

carried out. The patient had an uneventful postoperative course and was discharged from the hospital on postoperative day 6 .

\section{Discussion}

Splenosis is a term referring to ectopic implantation of splenic tissue into the peritoneal cavity. In splenectomized subjects, the process has been found to be beneficial and may provide protection against sepsis. The condition was first reported by Shaw and Shafi as an autopsy finding in 1937, ${ }^{1}$ and since then about 30 cases have been reported in the English literature. Thoracic splenosis typically presents as single or multiple subpleural masses at computed tomographic scan, although the radiologic presentation is nonspecific, mimicking mesothelioma, schwannoma, lymphoma, and lung metastases. Diagnosis results from nuclear medicine studies, cytologic examination, or intraoperative frozen section at surgery. There is no description of positron emission tomographic findings of the condition in the literature. Nuclear medicine studies include the use of ${ }^{99 \mathrm{~m}} \mathrm{Tc}$ sulphur colloid scintigraphy, ${ }^{111} \mathrm{In}$-labeled platelet scan, or ${ }^{99 \mathrm{~m}} \mathrm{Tc}$-labeled heat-damaged erythrocyte study. ${ }^{2}$ In a recent report, Prosch and associates $^{3}$ used the association of ferumoxides-enhanced magnetic resonance and scintigraphy to diagnose thoracic splenosis that presented as multiple pleural and mediastinal lesions. Despite occasional reports of splenosis diagnosed only by nuclear medicine studies, most authors agree that definitive diagnosis requires a cytologic or histologic examination. Fine-needle aspiration has been reported by most authors to be of little utility owing to its low sensitivity. There are, however, some reports of cytologic diagnosis by means of Tru-Cut needle biopsy (Baxter International, Inc, Deerfield, Ill) or fine-needle aspiration cytology. 4 

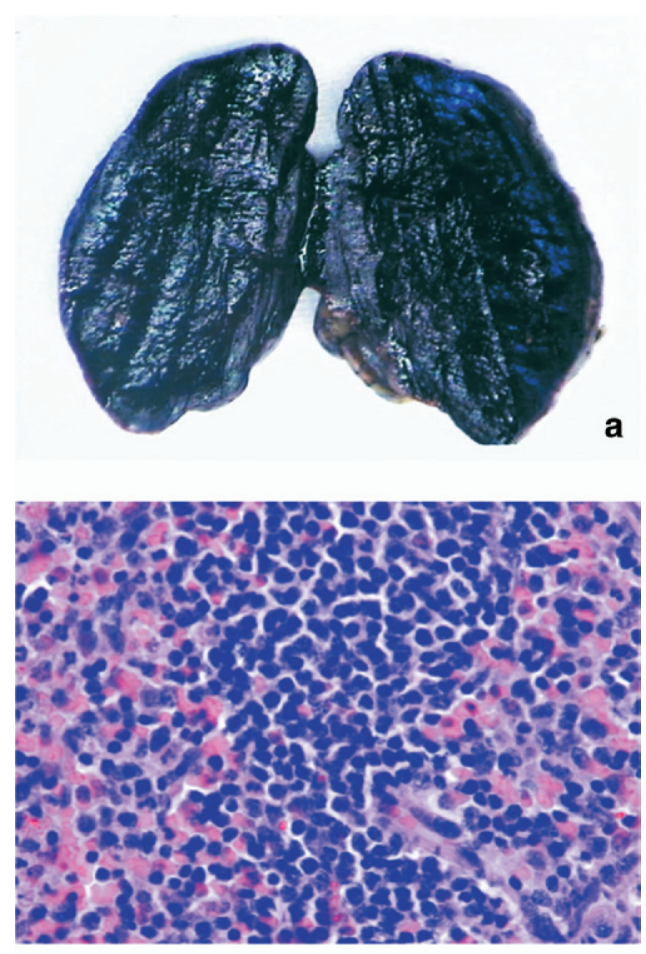

b

Figure 2. The surgical specimen was soft and displayed, at the cut surface, a brown color with small white dots (a). Histologically, typical benign spleen tissue with lymphocytic aggregates in a highly vascular background of sinusoidal structures was present (b).

Ultimately, most patients receive a definitive diagnosis at thoracotomy. Exploration may be undertaken by video-assisted thoracic surgery or thoracotomy. ${ }^{5,6}$ At surgical examination, the lesions may be single or multiple, pleura-based or mediastinal, or even intraparenchymal, thereby mimicking a metastatic dissemination. The size of the lesions may range from a few millimeters up to $6 \mathrm{~cm}$. Frozen section is almost always diagnostic. It is important that once the diagnosis of thoracic splenosis is made intraoperatively, no further resection of the lesions be undertaken to preserve any remnant of splenic function by the intrathoracic splenic tissue.

In conclusion, intrathoracic splenosis is a rare paraphysiologic condition of vicarious splenic function after surgical or traumatic removal of the spleen. Clinical and radiologic appearance may be misleading. Nuclear medicine studies and cytologic examination may on rare occasions provide a diagnosis. Most often, surgical exploration with frozen section of the lesion is needed to confirm the diagnosis and to rule out intrathoracic neoplasms. If possible, no further resection other than that needed for biopsy should be carried out to preserve as much splenic tissue as possible as protection against sepsis.

\section{References}

1. Shaw AFB, Shafi A. Traumatic autoplastic transplantation of splenic tissue in man with observations on the late results of splenectomy in six cases. J Pathol. 1937;45:215-35.

2. Hagman TF, Winer-Muram HT, Meyer CA, Jennings SG. Intrathoracic splenosis: superiority of technetium Tc99m heat-damaged RBC imaging. Chest. 2001;120:2097-8.

3. Prosch H, Oschatz E, Pertusini E, Mostbeck G. Diagnosis of thoracic splenosis by ferumoxides-enhanced magnetic resonance imaging. $J$ Thorac Imaging. 2006;21:235-7.

4. Gaines JJ, Crosby JH, Kamath V. Diagnosis of thoracic splenosis by tru-cut needle biopsy. Am Rev Respir Dis. 1986;133:1199-201.

5. Tsunezuka Y, Sato H. Thoracic splenosis; from a thoracoscopic viewpoint. Eur J Cardiothorac Surg. 1998;13:104-6.

6. Thourani VH, Sharma J, Duarte IG, Miller JI Jr. Intrathoracic splenosis. Ann Thorac Surg. 2005;80:1934-6. 